\title{
Thermal Analysis for Ice Rink Cooling and Building Heating Systems with Underground Storage Tank
}

\author{
Hakan Tutumlu ${ }^{1}$ and Recep Yumrutaş ${ }^{2}$
}

\begin{abstract}
In this study, the long-term performance of two thermal systems with the spherical underground thermal energy storage (TES) tank is investigated. The thermal systems are an ice rink cooling system, and ice rink cooling and house heating system with the TES tank, which consist of an ice rink, a chiller unit, a house to be heated, a heat pump and spherical underground TES tank. Two analytical models for the systems are developed for finding the thermal performance of the cooling and heating systems. The models are based on the solution of transient heat transfer problem outside the TES tank, energy requirements of the ice rink, chiller unit, heat pump and house. The solution of the problem is obtained using a similarity transformation and Duhamel superposition techniques. Analytical expressions for heat gain or loss of the ice rink, and for energy needs of the chiller unit, heat pump and house are derived as a function of inside design air, ambient air and water temperature in the TES tank. Analytical models are consisted of by combining of the solution equation and expressions for the each component of the thermal systems.

Interactive computer programs in Matlab based on the analytical models are prepared for finding an hourly variation of water temperatures in the TES tank, coefficients of performance (COP) of the chiller and heat pump, and timespan required to attain annually periodic operating conditions. Results indicate that COP of the chiller and heat pump, and operation time of span changes between 2-5 and 4-7, and 6-7 years respectively.
\end{abstract}

Keywords-Ice rink, chiller unit, energy storage tank, heat pump, cooling and heating system

\section{INTRODUCTION}

A ccording to the International Energy Agency (IEA), the World Energy requirement has doubled daily from 1970 [1]. Increasing usage of energy, welfare increase, and population growth are many factors. More than $80 \%$ of the used energy is obtained from natural gas, petroleum, and coal [2]. As a result, global carbon emissions have more than doubled since 1970, contributing to global warming and polluting the environment. Moreover, these fuel sources are not renewable and are constantly exhausted [3].

Hakan TUTUMLU ${ }^{1}$ is with the University of Firat, Elazig, 23119 TURKEY (corresponding author's phone: +090 424 2370000-5347; e-mail: htutumlu@firat.edu.tr).

Recep YUMRUTAȘ ${ }^{2}$ is with the University of Gaziantep, Gaziantep, 27310 TURKEY (author's phone: +090 34236011 04; e-mail: yumrutas@gantep.edu.tr).

Turkey energy ministry predicts that if more consumption of fossil fuel rise, it will be more polluted air in the winter season.

Renewable energy sources are being explored to reduce the use of natural gas, oil, and coal, and thus reduce environmental impacts. Renewable energy sources have recently come to a point of potential and capacity to significantly impact existing technology [4]. These resources naturally have the ability to renew themselves and, if a sensible rebate is achieved, can provide the energy needed to meet the world's energy needs [5]. Wind energy, hydropower, solar energy, biomass, biofuels and geothermal energy resources are among the renewable energy sources [1]. These energy sources are sustainable because they can be trusted in the future, and their use can significantly reduce the current environmental and social impacts of conventional fuels [5]. Although this research area has been going on for decades, the recent emphasis on precaution has led to widespread use. At present, about $17 \%$ of total global energy is derived from renewable sources [5]. The main contributors are biomass and hydro, but the wind and solar energy are expanding and will make a more significant contribution to continuous research and development [3-5].

Despite the accelerated growth of renewable energy sources, more than a majority of world's energy need is supplied from fossil fuels [6]. The increasing consumption of the fossil fuels in the heating system leads to realizing that global warming and rapid changes in climate needs to be reduced by developing green heating systems [7-8]. For this reason, national energy strategies of many countries are focused on the use of environmentally friendly, renewable and sustainable energy resources [9].

In this study, an analytical and computational model for an ice rink cooling system and building a heating system with underground TES tank is developed. The model consists of periodic solutions of transient heat transfer problem outside of TES tank, expressions for energy requirements of the chiller unit, heat pump, ice rink and building. COP of the cooling and heating systems are acquired by utilizing the storage temperature. The analytical expressions are derived as a function of inside design air, ambient air and water 
temperature in the TES tank.

Two computer programs in Matlab are developed in this study. The programs are prepared to investigate effects of water and ambient air temperature, earth type, Carnot efficiency ratio, storage tank size, the number of house and size of the ice rink on COP of the chiller unit and heat pump, and to find timespan required to attain annually periodic operating conditions. One of the programs is based on an analytical model for the ice rink cooling system with TES tank. The second program is prepared for the second analytical model of the ice rink cooling and building heating systems with TES tank. In the programs, hourly ambient air temperatures are used as input data. Hourly variation of water temperatures, COP of the chiller and heat pump units, and energy fractions for the systems are computed by the programs.

\section{DESCRIPTION OF THE ICE Rink COOLING AND BUILDING HEATING SySTEMS WITH UNDERGROUND STORAGE TANK}

The system is shown in Fig. 1 consists of five components, which are an underground thermal energy storage (TES) tank, heat pump for heating, chiller unit for cooling, and an ice rink to be cooled in a whole year.

The most significant component of the cooling and heating systems is the underground TES tank which provides energy savings and contributes to reductions in environmental pollution [10]. The energy exchange between the heat pump and chiller unit and the ground will improve the performance of cooling and heating systems. The ground is considered as large energy storage medium with large mass and stable temperature [11]. Therefore, the TES tank is very important for stored rejected energy from the cooling system of the ice rink, and also TES will be utilized as a heat sink of the chiller unit in operating time. Stored energy is used with a heat pump for heating of buildings in the winter season.

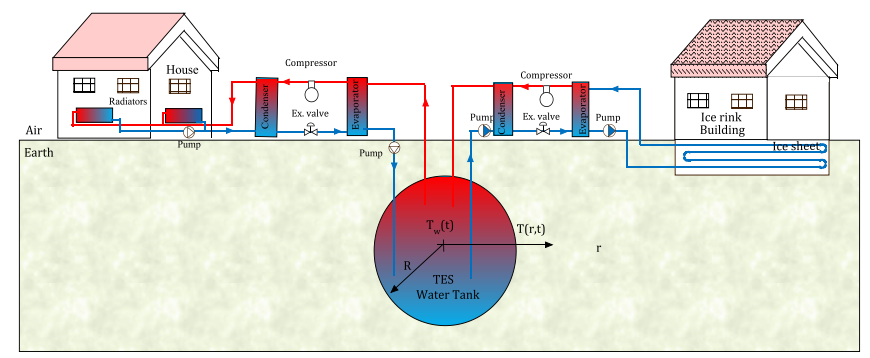

Fig. 1 Ice rink cooling and building heating systems with an underground TES tank

A heat pump is the important component of the heating system. It is connected to the thermal storage tank utilized as a heat source. Heat will be supplied to the building by the heat pump. The heat pump technology can reach a higher efficiency of energy for heating operation than conventional cooling operations for the reason that higher temperature for heating is provided by the underground environment and experiences show that less fluctuation of water temperature in the tank than ambient air temperature change. Stored energy in the thermal energy storage tank is extracted by a heat pump for heating of buildings only during winter season. The heat pump runs only when the temperature of water in the tank is inadequate to hold the building at required inside design air temperature. If the water temperature is below the required temperature, the heat pump increases the temperature of water in the tank before circulation through radiators in the buildings.

The significant component of the heating system is a house. A design heating load of $10 \mathrm{~kW}$ is assumed for the house with a $100 \mathrm{~m}^{2}$ floor area. It is thought that the heat is maintained to the building by the heat pump and water circulated through this heat pump.

\section{A. Transient Heat Transfer Problem around the TES Tank}

Transient heat problem inside earth outside the spherical TES tank and its initial and boundary conditions are given in spherical coordinates as follows;

$\frac{\partial^{2} \mathrm{~T}}{\partial^{2}}+\frac{2}{\mathrm{r}} \frac{\partial \mathrm{T}}{\partial \mathrm{r}}=\frac{1}{\alpha} \frac{\partial \mathrm{T}}{\partial \mathrm{t}}$

(1)

$\mathrm{T}(\mathrm{R}, \mathrm{t})=\mathrm{T}(\mathrm{t})$

(2)

$\mathrm{T}(\infty, \mathrm{t})=\mathrm{T}_{\infty}$

(3)

$\mathrm{T}(\mathrm{r}, 0)=\mathrm{T}_{\infty}$

(4)

The energy transferred to the tank is equal to the difference between sensible energy increase of the tank and the conduction heat loss from the tank to the surrounding soil.

$\mathrm{Q}=\rho_{\mathrm{w}} \mathrm{c}_{\mathrm{w}} \mathrm{V}_{\mathrm{w}} \frac{\mathrm{dT} \mathrm{w}}{\mathrm{dt}}-\mathrm{kA} \frac{\partial \mathrm{T}}{\partial \mathrm{r}}(\mathrm{R}, \mathrm{t})$

(5)

The transient heat transfer problem given by Equations (1-23-4-5) is transferred into dimensionless form by utilizing following dimensionless variables.

$$
\begin{array}{ll}
\mathrm{x}=\frac{\mathrm{r}}{\mathrm{R}} \quad \tau=\frac{\alpha \mathrm{t}}{\mathrm{R}^{2}} \quad \mathrm{q}=\frac{\mathrm{Q}}{4 \pi \mathrm{R} k \mathrm{~T}_{\infty}} \quad \mathrm{p}=\frac{\rho_{\mathrm{w}} \mathrm{c}_{\mathrm{w}}}{3 \rho \mathrm{c}} \\
\phi=\frac{\mathrm{T}-\mathrm{T}_{\infty}}{\mathrm{T}_{\infty}} \quad \phi_{\mathrm{w}}=\frac{\mathrm{T}_{\mathrm{w}}-\mathrm{T}_{\infty}}{\mathrm{T}_{\infty}} & \phi_{\mathrm{a}}=\frac{\mathrm{T}_{\mathrm{a}}-\mathrm{T}_{\infty}}{\mathrm{T}_{\infty}}
\end{array}
$$

The dimensionless transient temperature distribution in the earth surrounding the TES tank is obtained using Duhamel's superposition technique, which is given by the following expression. 
$\psi(\mathrm{x}, \tau)=\phi_{\mathrm{W}}(0)\left\{1-\operatorname{erf}\left(\frac{\mathrm{x}-1}{2 \sqrt{\tau}}\right)\right\}+\int_{0}^{\tau} \frac{\mathrm{d} \phi_{\mathrm{W}}(\xi)}{\mathrm{d} \xi}\left\{1-\operatorname{erf}\left(\frac{\mathrm{x}-1}{2 \sqrt{\tau-\xi}}\right)\right\} \mathrm{d} \xi$

If the solution for $\phi$ is now differentiated with respect to the dimensionless variables $\mathrm{x}$, the result evaluated at $\mathrm{x}=1$ and substituted into the equation, the following integrodifferential equation is obtained.

$\mathrm{q}=\mathrm{p} \frac{\mathrm{d} \phi_{\mathrm{W}}}{\mathrm{d} \tau}+\phi_{\mathrm{w}}(\tau)+\int_{0}^{\tau} \frac{\mathrm{d} \phi_{\mathrm{W}}(\xi)}{\mathrm{d} \xi} \frac{\mathrm{d} \xi}{\sqrt{\pi(\tau-\xi)}}$

(8)

Equation (8) can be discretized and solved for the dimensionless temperature of the water in the TES tank at the nth time increment to yield:

$$
\phi_{\mathrm{w}}\left(\tau_{\mathrm{n}}\right)=\frac{\mathrm{q}\left(\tau_{\mathrm{n}}\right)+\left[\frac{\mathrm{p}}{\Delta \tau}+\frac{1}{\sqrt{\pi \Delta \tau}}\right] \phi_{\mathrm{w}}\left(\tau_{\mathrm{n}-1}\right)-\sum_{\mathrm{i}=1}^{\mathrm{n}} \frac{2}{\phi_{\mathrm{w}}\left(\tau_{\mathrm{i}+1}\right)-\phi_{\mathrm{w}}\left(\tau_{\mathrm{i}}\right)}}{\sqrt{\pi \Delta \tau(\mathrm{n}-\mathrm{i})}}
$$

Equation (9) will be used to calculate the water temperature of the spherical TES. The term $q(\tau)$ in Eq. (9) represents the dimensionless net heat input rate to the TES tank. The heat input rate to the TES tank, $\mathrm{q}(\tau)$ is the difference between dimensionless heat collection rate by rejected energy from ice cooling system and the energy extracted by the heat pump, which is given by;

$$
\mathrm{q}(\tau)=\mathrm{q}_{\mathrm{u}}(\tau)-\mathrm{q}_{\mathrm{h}}(\tau)+\frac{\mathrm{w}(\tau)}{\gamma}
$$

where $\gamma$ is a dimensionless parameter, $\{4 * \mathrm{Rk} /(\mathrm{UA}) \mathrm{h}\}$, and $\mathrm{q}_{\mathrm{u}}($ $\tau)$ is the dimensionless available rejected energy rate collected. $\mathrm{q}(\tau)$ and $\mathrm{w}(\tau)$ are the dimensionless heat requirement of the building and the heat pump work, respectively. The $\mathrm{q}_{\mathrm{u}}(\tau), \mathrm{q}_{\mathrm{h}}(\tau)$ and $\mathrm{w}(\tau)$ are given in the following sections. Calculation of the hourly available rejected energy gain rate is adapted with the cooling system of the ice rink and it is summarized in the following section.

\section{B. Energy Analysis for Ice Rink}

Energy analysis of ice rink is made in this section. Firstly, the energy requirement for making ice sheet which is named as pre-cooling load, and then secondly, operating cooling load is very important part of total cooling load after working off the ice rink. Therefore, calculation of pre-cooling load and operating cooling load are to acquire the total cooling load of the ice rink.

Pre-cooling load, $\mathrm{Q}_{\mathrm{E}}$, is defined as; $\mathrm{Q}_{\mathrm{E}}=1.15\left(\mathrm{Q}_{\mathrm{F}}+\mathrm{Q}_{\mathrm{C}}+\mathrm{Q}_{\mathrm{SR}}+\mathrm{Q}_{\mathrm{b}-\mathrm{p}}\right)$

where $\mathrm{Q}_{\mathrm{F}}$ is water freezing load, $\mathrm{Q}_{\mathrm{C}}$ is concrete cooling load, $\mathrm{Q}_{\mathrm{SR}}$ is secondary cooling load, $\mathrm{Q}_{\mathrm{b}-\mathrm{p}}$ is the building and pumping heat (cool) load to be $0.0926\left(\mathrm{~A}_{\text {rink }}\right)$ and $1.15(\% 15)$ is system losses.[12].
Operating cooling load, $\mathrm{Q}_{\mathrm{oper}}$ is the total of convection heat gain $\mathrm{Q}_{\mathrm{CV}}(\mathrm{kW})$, radiation heat gains $\mathrm{Q}_{\mathrm{R}}$ and the heat gains due to conductions $\mathrm{Q}_{\mathrm{CD}}$ as follows:

$\mathrm{Q}_{\text {oper }}=\mathrm{Q}_{\mathrm{CV}}+\mathrm{Q}_{\mathrm{R}}+\mathrm{Q}_{\mathrm{CD}}$

(12)

Total cooling load, $\mathrm{Q}_{\mathrm{L}}$ is the sum of the evaporation load $\left(\mathrm{Q}_{\mathrm{E}}\right)$ and the operating cooling load $\left(\mathrm{Q}_{\mathrm{oper}}\right)$, which is given by [12].

$\mathrm{Q}_{\mathrm{L}}=\mathrm{Q}_{\mathrm{E}}$

\section{Energy Requirement of the Ice Rink Space}

The demand of cooling load of the ice rink will be represented as a function of outside air temperature which changes with time. Instantaneous heat gain load demands of the ice rink in the whole years may be represented as:

$\mathrm{Q}_{\mathrm{L}}(\mathrm{t})=(\mathrm{UA})_{\text {rink }}\left[\mathrm{T}_{\mathrm{a}}(\mathrm{t})-\mathrm{T}_{\mathrm{i}}\right]$

(14)

where $(\mathrm{UA})_{\text {rink }}$ is the UA-value of the rink, $\mathrm{T}_{\mathrm{i}}$ and $\mathrm{T}_{\mathrm{a}}(\mathrm{t})$ are the inside design air and ambient air temperatures, respectively. The energy demand of the ice rink, $\mathrm{Q}_{\mathrm{L}}(\mathrm{t})$ may also be expressed by:

$\mathrm{Q}_{\mathrm{L}}(\mathrm{t})=(\mathrm{UA})_{\text {rink-he }}\left[\mathrm{T}_{\mathrm{c}}(\mathrm{t})-\mathrm{T}_{\mathrm{i}}\right]$

where $(\mathrm{UA})_{\text {rink-he }}$ and $\mathrm{T}_{\mathrm{c}}(\mathrm{t})$ are UA-value for the load side heat exchanger in the rink and temperature of the refrigerant fluid in the load side heat exchanger located in the rink.

\section{Energy Requirement of the Chiller Unit}

The Chiller unit used in the cooling system absorbs heat in the ice rink and supplies heat to the underground TES tank. Cooling load for the ice rink may be represented by the product of the coefficient of performance ( $\mathrm{COP}$ cooling) of the chiller and chiller's compressor work:

$\mathrm{Q}_{\mathrm{L}}(\mathrm{t})=\mathrm{W}(\mathrm{t})\left(\mathrm{COP}_{\text {cooling }}\right)$

The performance of heat pump may be represented as:

$\mathrm{COP}_{\text {cooling }}=\frac{\mathrm{Q}_{\mathrm{L}}(\mathrm{t})}{\mathrm{W}(\mathrm{t})}=\frac{\mathrm{Q}_{\mathrm{L}}(\mathrm{t})}{\mathrm{Q}_{\mathrm{h}}(\mathrm{t})-\mathrm{Q}_{\mathrm{L}}(\mathrm{t})}$

where $\mathrm{W}(\mathrm{t})$ is the work consumption of compressor, and $\mathrm{Q}_{\mathrm{h}}(\mathrm{t})$ is the heat rejected to the TES tank. The COP of the chiller can be calculated using the approach given by Tarnowski [13-14-15-16]. He expresses the actual COP of the chiller by multiplying the Carnot COP of the unit by a Carnot factor:

$\mathrm{COP}_{\text {cooling }}=\beta \frac{\mathrm{T}_{\mathrm{c}}}{\mathrm{T}_{\mathrm{w}}(\mathrm{t})-\mathrm{T}_{\mathrm{c}}}$

where $\beta$ is the Carnot factor and changes between 0 and 1 . Clearly, Carnot factor is 1 for Carnot refrigeration cycle. Equations (15) and (14) may be combined and solved for $\mathrm{T}_{\mathrm{c}}$. When $\mathrm{T}_{\mathrm{c}}$ is substituted into Eq. (18), and dimensionless parameters are given in Eq. (6) are used, we obtain 


$$
\mathrm{COP}_{\text {cooling }}=\beta \frac{\mathrm{u}\left[\phi_{\mathrm{i}}-\phi_{\mathrm{a}}(\tau)\right]+\phi_{\mathrm{i}}+1}{\mathrm{u}\left[\phi_{\mathrm{i}}-\phi_{\mathrm{a}}(\tau)\right]-\phi_{\mathrm{i}}+\phi_{\mathrm{w}}(\tau)}
$$

When equations (15) and (19) are inserted into Eq. (17), the dimensionless compressor work may be expressed as

$$
\mathrm{w}=\frac{\left[\phi_{\mathrm{a}}(\tau)-\phi_{\mathrm{i}}\right]\left\{\mathrm{u}\left[\phi_{\mathrm{a}}(\tau)-\phi_{\mathrm{i}}\right]-\phi_{\mathrm{i}}+\phi_{\mathrm{w}}(\tau)\right\}}{\beta\left\{\mathrm{u}\left[\phi_{\mathrm{i}}-\phi_{\mathrm{a}}(\tau)\right]+\phi_{\mathrm{i}}+1\right\}}
$$

The parameter u in Equations (19) and (20) is defined as,

$$
\mathrm{u}=\frac{(\mathrm{UA})_{\text {rink }}}{(\mathrm{UA})_{\text {rink he }}}=\frac{\mathrm{T}_{\mathrm{i}}-\mathrm{T}_{\mathrm{c}}}{\mathrm{T}_{\mathrm{a}}-\mathrm{T}_{\mathrm{i}}}
$$

\section{E. Hourly Useful Rejected Energy Collection Rate}

Chiller unit of ice rink is thought to charge rejected heat into the thermal storage tank. It may be acquired from the expression for useful energy collection rate, The hourly useful energy collection rate, $\mathrm{Q}_{\mathrm{u}}(\mathrm{t})$ can be determined by the formula given by

$$
\mathrm{Q}_{\mathrm{u}}(\mathrm{t})=\mathrm{Q}_{\mathrm{L}}(\mathrm{t})\left(1+\frac{1}{\mathrm{COP}_{\text {cooling }}}\right)
$$

where COP cooling is the performance of cooling for the ice rink. $\mathrm{Q}_{\mathrm{L}}$ is the total heat gain of the ice rink.

\section{F. Energy Requirement of the Building}

The demand of heating load for the building may be represented as a function of outside air temperature which alters with time. Instantaneous heating load of the house in the winter season may be represented as:

$$
\mathrm{Q}_{\mathrm{h}}(\mathrm{t})=(\mathrm{UA})_{\mathrm{h}}\left[\mathrm{T}_{\mathrm{i}}-\mathrm{T}_{\mathrm{a}}(\mathrm{t})\right]
$$

(23)

where, $(\mathrm{UA})_{\mathrm{h}}$ is the UA-value of the building, $\mathrm{T}_{\mathrm{i}}$ and $\mathrm{T}_{\mathrm{a}}(\mathrm{t})$ are the inside design air and ambient air temperatures, respectively. Energy requirement of the house, $\mathrm{Q}_{\mathrm{h}}(\mathrm{t})$ may also be expressed by:

$$
\mathrm{Q}_{\mathrm{h}}(\mathrm{t})=(\mathrm{UA})_{h e}\left[\mathrm{~T}_{\mathrm{h}}(\mathrm{t})-\mathrm{T}_{\mathrm{i}}\right]
$$

\section{(24)}

where (UA)he and Th(t) are UA-value for the load side heat exchanger and temperature of fluid in the load side heat exchanger located in the house. Although transient heat transfer was considered in Section A when formulating the heat transfer problem in the earth surrounding the thermal storage tank, the formulation presented by Equation (9) for computation of the building heating load is a "quasi-steady formulation" which neglects thermal capacity effects of the building structure.

\section{G. Derived Equations for the Energy Demand of the Heat Pump for Heating System}

The heat pump is a device that extracts heat from the TES tank and supplies heat to the building. Heat supplied to the building can be presented by the product of the performance of the heat pump and heat pump work:

$$
\mathrm{Q}_{\mathrm{h}}(\mathrm{t})=\mathrm{W}(\mathrm{t})(\mathrm{COP})_{\text {heating }}
$$

The performance of the heat pump can be presented as:

$\mathrm{COP}_{\text {heating }}=\frac{\mathrm{Q}_{\mathrm{h}}(\mathrm{t})}{\mathrm{W}(\mathrm{t})}=\frac{\mathrm{Q}_{\mathrm{h}}(\mathrm{t})}{\mathrm{Q}_{\mathrm{h}}(\mathrm{t})-\mathrm{Q}_{\mathrm{L}}(\mathrm{t})}$

The performance of the heat pump was calculated utilizing the approach given in section D. The Carnot efficiency, $\beta$ is equal to the ratio of actual $\mathrm{COP}_{\text {heating }}$ of a heat pump to Carnot $\mathrm{COP}_{\mathrm{c}}$.

$\beta=\frac{\mathrm{COP}_{\text {heating }}}{\mathrm{COP}_{\mathrm{c}}}$

Carnot $\mathrm{COP}_{c}$ may be represented as a function of the source $\left(\mathrm{T}_{\mathrm{wh}}\right)$ and sink $\left(\mathrm{T}_{\mathrm{h}}\right)$ temperatures as:

$\mathrm{COP}_{\mathrm{c}}=\frac{\mathrm{T}_{\mathrm{h}}(\mathrm{t})}{\mathrm{T}_{\mathrm{h}}(\mathrm{t})-\mathrm{T}_{\mathrm{wh}}(\mathrm{t})}$

(28)

Combining equations of (27) and (28), yields:

$C O P_{\text {heating }}=\beta\left(\frac{T_{h}(t)}{T_{h}(t)-T_{w h}(t)}\right)$

When the equations (9) and (10) are combined and solved for $T_{h}(t)$ and the resulting expression for $T_{h}(t)$ is substituted into Eq. (29), $\eta_{c}$ can be expressed in dimensionless form as follows:

$\mathrm{COP}_{\text {heating }}=\beta \frac{\mathrm{u}\left[\phi_{\mathrm{i}}-\phi_{\mathrm{a}}(\tau)\right]+\phi_{\mathrm{i}}-\phi_{\mathrm{wh}}(\tau)}{\mathrm{u}\left[\phi_{\mathrm{i}}-\phi_{\mathrm{a}}(\tau)\right]+\phi_{\mathrm{i}}+1}$

Inserting equations (9) and (30) into Eq. (25), the dimensionless compressor work may, w, be obtained in dimensionless form as follows:

$\mathrm{w}=\frac{\left[\phi_{\mathrm{a}}(\tau)-\phi_{\mathrm{i}}\right]\left\{\mathrm{u}\left[\phi_{\mathrm{i}}-\phi_{\mathrm{a}}(\tau)\right]+\phi_{\mathrm{i}}-\phi_{\mathrm{wh}}(\tau)\right\}}{\beta\left\{\mathrm{u}\left[\phi_{\mathrm{i}}-\phi_{\mathrm{a}}(\tau)\right]+\phi_{\mathrm{i}}+1\right\}}$

where, $\phi_{\mathrm{i}}$ is dimensionless inside design air temperature, $\phi_{\mathrm{a}}(\mathrm{t})$ and $\phi_{w_{-} \text {heating }}(t)$ are dimensionless outside air and TES tank water temperature for the winter season, respectively. The parameter $u$ in Equations (30-31) is the ratio of $(\mathrm{UA})_{\mathrm{h} \text {-value }}$ for the house to (UA) $)_{\text {he-value }}$ for load side heat exchanger, which is given by;

$\mathrm{u}=\frac{(\mathrm{UA})_{\mathrm{h}}}{(\mathrm{UA})_{\mathrm{he}}}=\frac{\mathrm{T}_{\mathrm{h}}-\mathrm{T}_{\mathrm{i}}}{\mathrm{T}_{\mathrm{i}}-\mathrm{T}_{\mathrm{a}}}$

\section{H.Method and Some Parameters}

A computer program in Matlab based on the present analytical model was prepared to carry out the numerical computations. The computational procedure was used to find the temporal variation of water temperature in the TES tank and other performance parameters such as the COP of the chiller. The program uses an operational procedure to 
calculate these parameters for nearly 10 years. Our program is working nearly 25 minutes at special computer properties which have 6 GB RAM and $2.6 \mathrm{GHz}$ microprocessor.

Computer programs are developed in Matlab. All the input parameters of the program are given below in detail.

In the program, there are some input parameters which are thermo-physical properties of the earth, climatic data and the data for the ice rink. Thermo-physical properties of the three types of earth (sand, coarse graveled and limestone) considered in the present study are taken from Ozisik [17] and listed in Table I.

TABLE I

PROPERTIES OF THE GEOLOGICAL STRUCTURES [17]

\begin{tabular}{ccccc}
\hline Earth Type & $\begin{array}{c}\text { Conductivity } \\
(\mathrm{W} / \mathrm{mK})\end{array}$ & $\begin{array}{c}\text { Diffusivity } \\
\left(\mathrm{m}^{2} / \mathrm{sec}\right)\end{array}$ & $\begin{array}{c}\text { Specific heat } \\
(\mathrm{J} / \mathrm{kgK})\end{array}$ & $\begin{array}{c}\text { Heat } \\
\text { capacity } \\
\left(\mathrm{kJ} / \mathrm{m}^{3} \mathrm{~K}\right)\end{array}$ \\
\hline Coarse graveled & 0.519 & $1.39 \times 10-7$ & 1842 & 3772 \\
Limestone & 1.3 & $5.75 \times 10-7$ & 900 & 2250 \\
Sand & 0.3 & $2.50 \times 10-7$ & 800 & 1200 \\
\hline
\end{tabular}

The initial storage temperature is assumed to be equal to the deep ground temperature at the start of the computations. The deep ground temperature is taken $15{ }^{\circ} \mathrm{C}$ and the whole year inside design air temperature in the ice rink is taken 12 ${ }^{\circ} \mathrm{C}$. Also in the winter season inside design air temperature is taken $20{ }^{\circ} \mathrm{C}$. Hourly outside air temperatures are taken from Meteorological Station for Gaziantep.

In the calculations, Carnot factor is taken 0.4 and the volume of the tank is taken $200 \mathrm{~m}^{3}$ unless otherwise specified. The product of heat transfer coefficient and the area for the house (UA) rink is taken to be $1400 \mathrm{~W} /{ }^{\circ} \mathrm{C}$. Taking $\mathrm{T}_{\mathrm{i}}=12{ }^{\circ} \mathrm{C}$ and $\mathrm{T}_{\mathrm{c}}=-5{ }^{\circ} \mathrm{C}$ and using the summer outside design temperature $\mathrm{T}_{\mathrm{a}}=39{ }^{\circ} \mathrm{C}$ for the city of Gaziantep, $\mathrm{u}$ value defined in Eq. (32) is determined to be 0.6 for cooling of the ice rink. But for heating of space, $\mathrm{u}$ is taken to be 1 defined in equation (30). And also, for heating of space taking $\mathrm{T}_{\mathrm{i}}=20^{\circ} \mathrm{C}$ $\mathrm{T}_{\mathrm{h}}=-9{ }^{\circ} \mathrm{C}$ for winter design condition. Data for the ice rink are listed in Table II.

TABLE II

SOME NECESSARY PARAMETER FOR ENERGY ANALYSIS OF ICE RINK [12]

\begin{tabular}{lll} 
Symbol & Parameter & Values \\
\hline $\mathrm{A}_{\mathrm{c}}$ & Concrete Area & $100 \mathrm{~m}^{2}$ \\
$\mathrm{~A}_{\text {ice }}$ & İce Area & $100 \mathrm{~m}^{2}$ \\
$A_{\text {rink }}$ & Rink Area & $100 \mathrm{~m}^{2}$ \\
$A_{\text {ceiling }}$ & Ceiling Area & $110 \mathrm{~m}^{2}$ \\
$C_{p, c}$ & Specific heat of concrete & $0.67 \mathrm{~kJ} / \mathrm{kg} . \mathrm{K}$ \\
$r$ & Latent heat of freezing water & $334 \mathrm{~kJ} / \mathrm{kg}$ \\
$T_{\text {ceiling }}$ & Ceiling temperature & $18.80{ }^{\circ} \mathrm{C}$ \\
$T_{D}$ & Distribution temperature & $18.80{ }^{\circ} \mathrm{C}$ \\
$T_{c, i}$ & Initial temperature of concrete & $2{ }^{\circ} \mathrm{C}$ \\
$T_{c, f}$ & Final temperature of concrete & $-4{ }^{\circ} \mathrm{C}$ \\
$T_{f}$ & Flood water temperature & $60{ }^{\circ} \mathrm{C}$ \\
$T_{i c e}$ & Ice temperature & $-2{ }^{\circ} \mathrm{C}$ \\
$T_{i n}$ & Inside design temperature & $12{ }^{\circ} \mathrm{C}$ \\
$T_{S R, i}$ & Initial temperature of secondary coolant & $5{ }^{\circ} \mathrm{C}$ \\
$T_{S R, f}$ & Final temperature of secondary coolant & $-7{ }^{\circ} \mathrm{C}$ \\
& Initial temperature of water & $11{ }^{\circ} \mathrm{C}$ \\
$T_{w, i}$ & Mole fraction of water vapor in air & $6.6^{*} 10^{-3}$ \\
$x_{a i r}$ & Mole fraction of water vapor in saturated & $3.6^{*} 10^{-3}$ \\
$x_{i c e}$ & ice & \\
& Flood water volume & $31^{*} 10^{-3} \mathrm{~m}^{3}$ \\
\hline & Angle factor, ceiling to interface & 0.65 \\
\hline
\end{tabular}

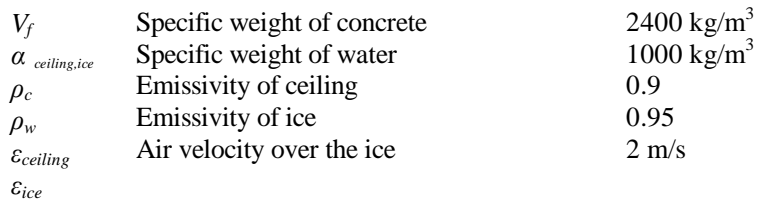

In additionally, dimensionless cooling load and heating load are calculated for all months of the whole year using assumed hourly average temperatures, the inside design air temperature, and the hourly outside temperatures.

\section{RESULT ANALYSIS OF ICE RINK COOLING AND BUILDING HEATING SYSTEMS WITH UNDERGROUND STORAGE TANK}

Hourly average weather data are used in the heating analysis. The thermal energy store and heat pump have a significant role in the heating operation of buildings. Storage volume levels greatly affect the temperature of the water in the thermal storage tank. Another important thing, Levels of storage temperature affect greatly the performance of the heating system.

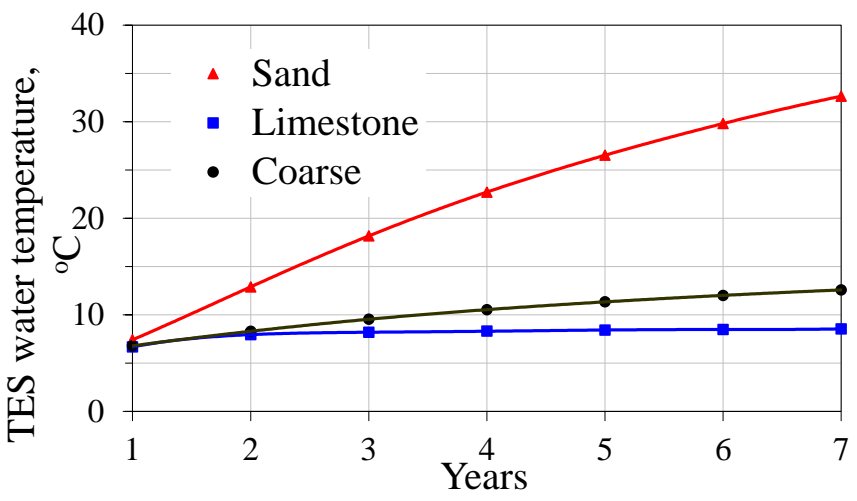

Fig. 2 Annual temperature variation of water in the TES tank for February $\left(\mathrm{A}_{\mathrm{ice}}=250 \mathrm{~m}^{2}, \mathrm{CE}=40 \%, \mathrm{~V}=100 \mathrm{~m}^{3}, \mathrm{NOH}=5\right)$

Long time variation of storage water temperature encircled with three varying types of the earth for February is indicated in Fig. 2. This Figure indicates that sand is higher TES tank temperatures when compared with coarse graveled or limestone.

Comparison of the thermos-physical properties of the three earth types as listed in Table I presents that both heat conduction coefficient and thermal diffusivity values for sand are lower than suitable values of these properties for the other types of earth. Also, the heat capacity of sand is greater than the corresponding values of this property for the other types of earth. Another observation depicted in Fig.2 is rapid differentiation of thermal storage tank temperatures during the first few years of operation. Differentiation of the thermal storage tank temperatures reduces until the fifth year of operation for all geological structures, and thermal storage tank temperatures do not change after the fifth year of operation indicating periodic operating conditions thereafter. 

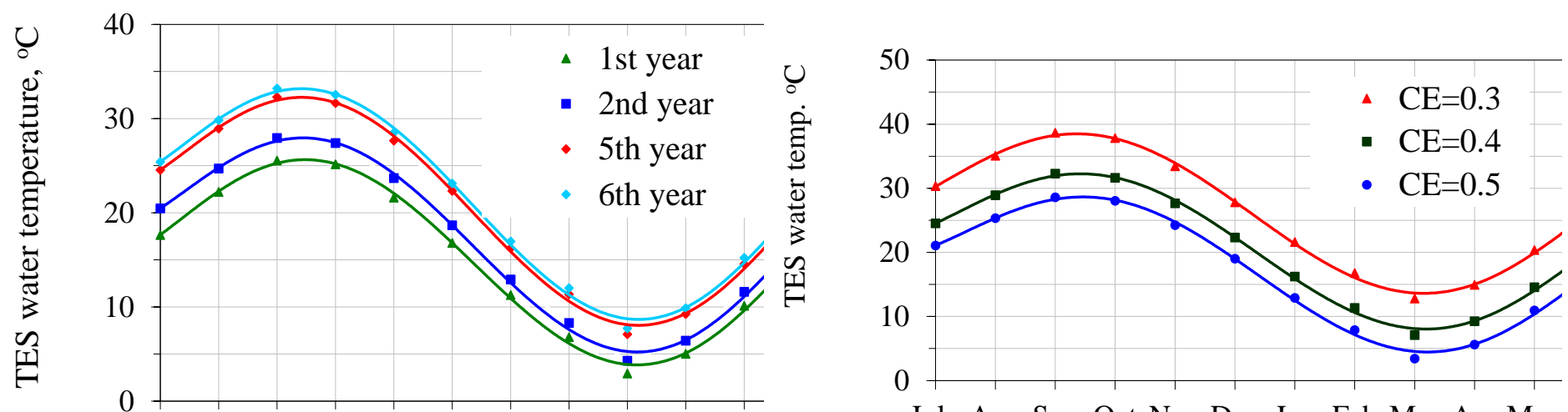

July Aug Sep Oct Nov Dec Jan Feb Mar Apr Mas

Fig. 3 Annual temperature variation of water in the TES tank with a number of operation years. (Coarse graveled, $\mathrm{A}_{\mathrm{ice}}=250 \mathrm{~m}^{2}, \mathrm{CE}=40$ $\left.\%, \mathrm{~V}=100 \mathrm{~m}^{3}, \mathrm{NOH}=5\right)$

Fig. 3 depicts whole year variation of water in the thermal storage tank for coarse graveled type earth during the first, second, fifth, and sixth years of operation. It is indicated from the figure that yearly periodic operating conditions are attained after the fifth year of operation. Numbers of houses were taken 5 buildings for heating of these spaces.

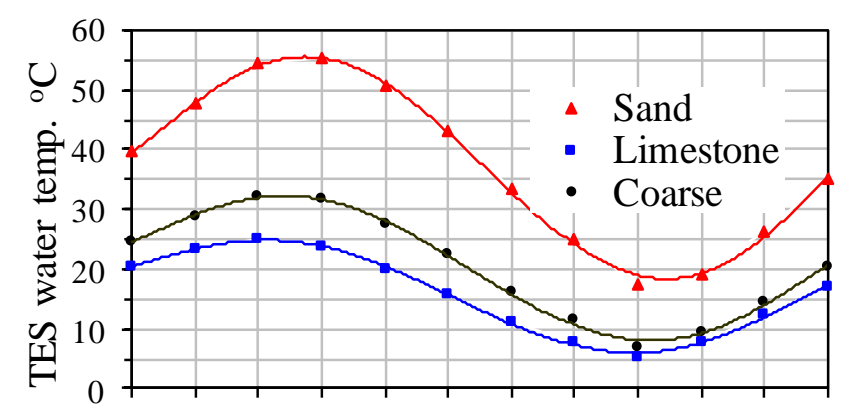

July Aug Sep Oct Nov Dec Jan Feb Mar Apr May Jun Months

Fig. 4 Effect of earth type on annual temperature variation of water in the TES tank during the fifth year of operation $\left(A_{\text {ice }}=250 \mathrm{~m}^{2}\right.$, $\mathrm{CE}=40 \%, \mathrm{~V}=100 \mathrm{~m}^{3}, \mathrm{NOH}=5$ )

Fig. 4 demonstrates all year differentiation of storage temperature in the thermal storage tank throughout the fifth year of operation for three various geological earth types; coarse graveled earth, limestone, and sand. It is observed that the highest temperatures are at the end of summer and the lowest ones are at the end of winter. A heat pump does not run in summer months for heating while the thermal storage water is charged by rejected energy resulting in a raise in the thermal storage water temperature in all year. In the end of heat energy removing from the thermal storage water by the heat pump throughout cooling operation, the temperature of the water in the thermal storage reduces gradually toward the end of the winter season and the lowest store temperature occurs at the end of winter. It is obvious that the highest stored water temperatures were attained when the thermal storage tank was enclosed with coarse graveled earth, and the lowest one is attained for the limestone. $A_{i c e}=250 \mathrm{~m}^{2}, V=100 \mathrm{~m}^{3}, \mathrm{NOH}=5$ )

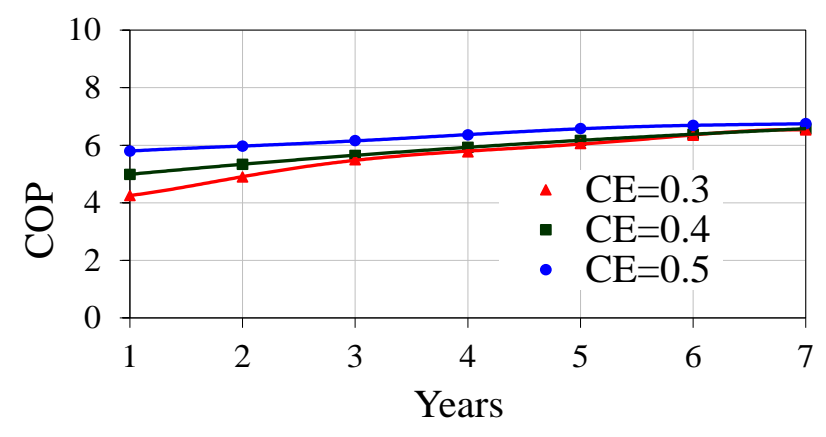

Fig. 6 Effect of $\mathrm{CE}$ on Performance of the heat pump (Coarse gravelled, $A_{\text {ice }}=250 \mathrm{~m}^{2}, \mathrm{~V}=100 \mathrm{~m}^{3}, \mathrm{NOH}=5$ )

A practically reasonable $\mathrm{CE}$ value was used in the present study. It is known that actual COP depends on the types and size of a real heat pump at different temperature lifts. Results attained for monthly variation of the TES tank temperature during the fifth year of operation and long-term variation of COP are shown in Figures 5 and 6, respectively. Higher CE values yield lower TES water temperatures and this is depicted in Fig. 5. A higher CE means a higher amount of heat extraction from the tank for the same heating load, and as a result of this, the water temperature in the TES reduces.

Effect of CE on the TES tank temperature is low as it is observed in Figure 5. But, its effect on the COP is high as observed in Fig. 6 Performance rises with years until yearly periodic operational conditions are obtained. Yearly performance value does not alter once annually periodic operational conditions are obtained.

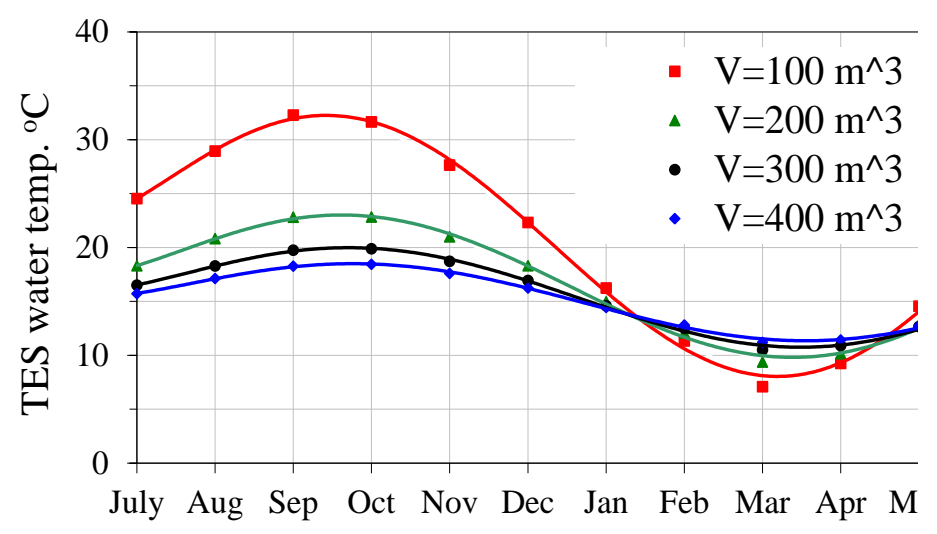

Fig. 7 Effect of storage volume on whole year temperature variation 
of water in the storage tank during the fifth year of operation (Coarse gravelled, $\mathrm{A}_{\mathrm{ice}}=250 \mathrm{~m}^{2}, \mathrm{CE}=40 \%, \mathrm{NOH}=5$ )

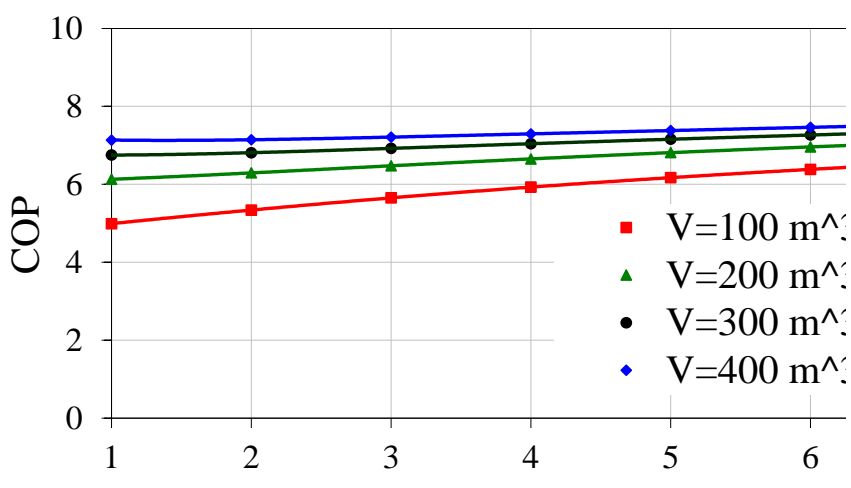

Fig. 8 Variation of Performance with tank volume and operation time (Coarse gravelled, $\mathrm{A}_{\mathrm{ice}}=250 \mathrm{~m}^{2}, \mathrm{CE}=40 \%, \mathrm{NOH}=5$ )

Figures 7 and 8 were prepared to accent influences of the storage tank size on system performance. Fig. 7 indicates the variation of water temperature in the thermal water storage tank for four different volumes during the fifth year operation. It can be observed that amplitude of the water temperature increases when the tank size is decreased. Water temperature of the TES tank is lowest but stays above $0{ }^{\circ} \mathrm{C}$ throughout January, February and March when the tank volume is $100 \mathrm{~m}^{3}$. Reduces in the TES tank temperature will reduce evaporation temperature of the refrigeration fluid in the heat pump cycle. This, in turn, raises the difference between evaporating and condensing temperatures resulting in a rise in heat pump work and reduces the heat pump performance. On the other hand, as the temperature difference between the sink and the source reduces, work needed by the heat pump reduces. Differentiation of the performance of the heat pump unit with years is observed in Figure 8 for four different tank volumes. Performance rises with the TES tank size. It rises up to the fifth year of operation for all tank sizes. Alter in performance is negligibly small after the fifth year. It is also observed in this figure that the altering in performance is small when the tank volume is raised from $300 \mathrm{~m}^{3}$ to $400 \mathrm{~m}^{3}$. As the heating necessities of the houses reduce, the COP rises.

We note that study results, while available for systems with TES tanks buried at significantly depths below the ground surface, will not be available for systems with TES tanks buried near to the ground surface. Because this is the temperature field outside TES tanks located near to the ground surface will be three dimensional in real structure due to the non-negligible effect of the boundary condition at the ground surface. A solution of the three-dimensional problem using the Duhamel's superposition principle is not possible and such a three-dimensional analysis is beyond the scope of the present investigation.

\section{CONCLUSIONS}

A program model for estimation of long the term performance of ice rink cooling systems and heating of building with heat storage were presented. The method of approach is based on attaining on the computer and the software developed may be applied to obtain optimum parametric values in addition to that storage volume, an ice rink area, the number of the house for heating and system size.

A hybrid analytical and computational model for finding long term performance of an ice rink cooling system and heating system with an underground thermal energy storage
(TES) tank is presented in this study. A computer code based on the model was develop and used to investigate the effects of number of operation years, thermo-physical properties of earth surrounding the TES tank, Carnot efficiency (CE) of the Chiller, storage volume, number of house for heating and ice rink area on the TES tank temperature and on thermal performance of the system considered. Results indicate that an operational time span of 5 to 7 years will be sufficient for the system under investigation to reach an annually periodic operating condition. Thermo-physical properties of earth around the tank effects the performance of the system and sand earth yields the best thermal performance from within the three earth types considered in this study. CE has a small effect on the TES tank temperature while having a stronger effect on the COP of the chiller and COP of the heating system.

The present study shows us technical feasibility of energy storage in deep earth. Further efforts are required on analytical modelling and experimentation of spherical thermal storages with heat pumps aimed cooling systems and/or heating systems.

\section{REFERENCES}

[1] Quaschning V., Renewable energy and climate change. Chichester, West Sussex, UK: Wiley; 2010.

[2] International Energy Agency, Key world energy statistics. [Online]. Available:/http://www.iea.org/newsroomandevents/news/2013/october/key -world-energy-statistics-2013-now-available.html); 2013 [Accessed 16.06.15]

[3] Lefebvre D. and Tezel H.F., A review of energy storage technologies with a focus on adsorption thermal energy storage processes for heating applications., Renewable and Sustainable Energy Reviews; 2015

[4] Dincer I, Rosen MA. Thermal energy storage: systems and applications. Chichester: John Wiley \& Sons; 2011.

[5] Elliott D. Renewables: a review of sustainable energy supply options. Great Britain: Institute of Physics; 2013.

[6] International Energy Agency. World energy outlook 2012 factsheet . Available from: httpwww.worldenergyoutlook. orgmediaweowebsite2012factsheets.pdf.

[7] Yaglı H., Koc Y., Koc A., Gorgulu A., Tandiroglu A., Parametric optimization and exergetic analysis comparison of subcritical and supercritical organic Rankine cycle (ORC) for biogas fueled combined heat and power (CHP) engine exhaust gas waste heat. Energy; 2016

[8] Mathiesen BV, Lund H, Connolly D, Wenzel H, Østergaard PA, Moller B, et al. $€$ Smart energy systems for coherent $100 \%$ renewable energy and transport solutions. Appl Energy 2015;145: 139-54.

[9] Kuyumcu M., Tutumlu H., Yumrutas R., Performance of a swimming pool heating system by utilizing waste energy rejected from an ice rink with an energy storage tank. Energy Conversion and Management; 2016, page: 349-357

[10] Novo, A.V., Bayon J.R., Castro-Fresno D., Rodriguez-Hernandez J. (2010). Review of seasonal heat storage in large basins: Water tanks and gravel-water pits. Applied Energy. 87, 390-397.

[11] Yumrutas, R., Unsal, M. (2000). Analysis of solar aided heat pump systems with seasonal thermal energy storage in surface tanks. Energy. 25, 1231-1243.

[12] Caliskan, H., Hepbasli, A. (2010). Energy and exergy analyses of ice rink buildings at varying reference temperatures. Energy and Building. 42,1418-1425.

[13] Yumrutas, R., Unsal, M. (2000). Analysis of solar aided heat pump systems with seasonal thermal energy storage in surface tanks. Energy. 25, 1231-1243.

[14] ASHRAE, Ice rinks in: ASHRAE Handbook-Fundamentals. (2006). American Society of Heating, Refrigerating, and Air-Conditioning Engineers Inc., Atlanta. Chapter 35.

[15] Yumrutas, R., Kunduz, M., Ayhan, T. (2003). Investigation of thermal performance of a ground coupled heat pump system with a cylindrical 
energy storage tank. International Journal of Energy Research. 27, 10511066.

[16] Tarnawski, V.R. (1989). Ground heat storage with double layer heat exchanger. International Journal of Energy Research. 13, 137-148.

[17] Ozisik, M.N. (1985). Heat Transfer: A Basic Approach, McGraw-Hill, New York. 